\title{
PBS KIDS Mathematics Transmedia Suites in Preschool Homes
}

\author{
Betsy McCarthy, Ph.D. \\ WestEd \\ 400 Seaport Court, Suite 222 \\ Redwood City, CA 94063 \\ 1-650-381-6441 \\ bmccart@wested.org
}

\author{
Linlin Li, Ph.D. \\ WestEd \\ 400 Seaport Court, Suite 222 \\ Redwood City, CA 94063 \\ 1-650-381-6449 \\ Ili@wested.org \\ Sara Atienza \\ WestEd \\ 400 Seaport Court, Suite 222 \\ Redwood City, CA 94063 \\ 1-650-381-6469 \\ satienz@wested.org
}

\author{
Michelle Tiu \\ WestEd \\ 400 Seaport Court, Suite 222 \\ Redwood City, CA 94063 \\ 1-650-381-6444 \\ mtiu@wested.org
}

\begin{abstract}
There is growing evidence that economically disadvantaged preschool children have less extensive mathematical knowledge than their middle-income peers $[14,37]$. This study addresses a program to foster low-income parents' support for their preschool children's mathematical development. Parents use PBS KIDS LAB web- and mobile-based mathematics transmedia game suites with their children. The study used a quasi-experimental, non-equivalent control group design, which assigned 90 parent/child dyads from two Head Start centers serving primarily low-income families to an intervention or comparison group. The results indicate that the intervention was positively associated with gains in children's knowledge and skills in mathematics $(p<.05)$, as measured by Test of Early Mathematics Ability (TEMA-3), after accounting for differences in baseline assessment results and participant demographic characteristics. The use of these age-appropriate digital media and related home activities also led to increases in parents' awareness of strategies to support their child's mathematics learning and their direct support of mathematics learning in the home environment.
\end{abstract}

\section{Categories and Subject Descriptors}

H5.m. Information interfaces and presentation (e.g., HCI): Miscellaneous.

\section{General Terms}

Documentation. Performance. Reliability.

Permission to make digital or hard copies of part or all of this work for personal or classroom use is granted without fee provided that copies are not made or distributed for profit or commercial advantage and that copies bear this notice and the full citation on the first page. Copyrights for thirdparty components of this work must be honored. For all other uses, contact the Owner/Author.

Copyright is held by the owner/author(s).

IDC '13, Jun 24-27 2013, New York, NY, USA

ACM 978-1-4503-1918-8/13/06.

http://dx.doi.org/10.1145/2485760.2485777

\section{Keywords}

Mathematics Education, Child-Computer Interaction, Parent Engagement, Early Childhood Education, Digital Media in Education, Technology Skills, Online Games

\section{INTRODUCTION}

During the summer of 2012, researchers conducted a study of the PBS KIDS Mathematics Transmedia Suites in preschool homes as part of the Ready To Learn Initiative developed by the Corporation for Public Broadcasting (CPB) and the Public Broadcasting Service (PBS) with funding from the U.S. Department of Education.

This paper describes a study of a collection of mathematics activities and games available to children on the PBS KIDS LAB website ${ }^{1}$. The focus of the study was on the efficacy of three PBS KIDS transmedia suites (The Cat in the Hat Knows A Lot About That, Curious George, and Sid the Science Kid and their accompanying parent support materials) in increasing preschoolers' mathematics skills and enhancing their parents' ability to support their children's mathematics learning in the home environment. The Cat in the Hat Knows A Lot About That series is designed to spark a love of learning and an interest in science in preschool-aged children. The Cat in the Hat Knows A Lot About That transmedia suite consists of four games that cover content such as shapes, patterns, classifying, and spatial visualizations. The Curious George series is designed to inspire children to explore science, engineering, and math in the world around them. The Curious George transmedia suite consists of 16 games that cover content related to counting and cardinality. The Sid the Science Kid series is designed to promote exploration, discovery, and science readiness among preschoolers. The Sid the Science Kid transmedia suite consists of nine games that cover content such as spatial reasoning, measurement, sorting, counting, and

\footnotetext{
${ }^{1}$ http://pbskids.org/lab
} 
patterns. Transmedia suites are comprised of thematically linked content presented across formats (e.g., short-form videos, online games, mobile phone activities, in-classroom digital games) and across media devices (e.g., computers, interactive whiteboards, tablets, mobile digital devices). The transmedia suites are engaging for both kids and parents, and use familiar characters from TV shows, stories, and books that the families know. There is solid educational content built into the transmedia suites. The games in the transmedia suites provide hints when children struggle in the games, and move to more academically difficult levels of play. The transmedia suites also use engaging narratives that give rise to curiosity and solution seeking, promoting logico-mathmatical thinking and learning in the context of discovery.

It was predicted that use of Ready To Learn's three PBS KIDS transmedia suites, along with the corresponding parent support materials available on PBS KIDS LAB, would increase preschool students' early mathematics abilities. In addition, it was predicted that use of the suites and related parent activities would increase parents' awareness of strategies to directly support their child's mathematics learning in the home environment. Specifically, the study applied a quasi-experimental design to address the following research questions:

- Does student use of the PBS KIDS transmedia suites increase children's knowledge and skills in mathematics?

- Does parents' awareness and support of their children's mathematics learning at home increase after interacting with their children around the suites and using support materials related to the suites?

\section{LITERATURE REVIEW}

\subsection{Participation in Preschool Programs}

There has been growing concern about an educational achievement gap among white and minority/low-income children entering kindergarten. The gap between school performance of children who are prepared to begin school, and those who are not, typically increases over time. Those who are not prepared fall farther behind - later remediation does not help after the fact [12]. Studies have shown that early childhood education can have a mitigating effect on the lack of preparation and the ensuing achievement gap.

Participation in preschool programs has been found to have a relatively large and enduring effect on school achievement and child wellbeing [34]. Such long-term effects of early childhood intervention have been traceable to a combination of school support and family support experiences [33]. Variables (such as pre-kindergarten experience, motivation, mobility, and parent involvement) that are directly alterable by families and schools significantly influence, either directly or indirectly, early school outcomes [32].

One way to ensure quality early childhood education programming is through improved curriculum. Starkey, Klein, \& Wakeley [36] conducted a pre-kindergarten mathematics intervention by developing new mathematics curriculum and complementary home activities. This curriculum was implemented in public and private preschools serving low- and middle-income families. The authors found a significant socio-economic-related gap in mathematical knowledge (arithmetic, space and geometry, measurement, patterns, and logical relations) at the beginning of the intervention year. By the end of the intervention year, the results demonstrated significantly enhanced math knowledge of children at both levels of socio-economic status; however, low-income children acquired more knowledge, relative to their starting point, than middle-income children [36].

\subsection{Parent Involvement and Engagement}

Parent support and engagement in early childhood education has long been touted as a positive influence on a child's academic achievement, most especially in low-income and minority families [3,9]. Early education coupled with parent involvement provides cognitive advantage at school entry that initiates a positive chain of effects that leads to better school performance and adjustment, and that over time culminates in higher rates of school completion and lower drop-out rates $[17,33]$. And the benefits are believed to persist beyond kindergarten. For example, Gonzales-DeHass et al. [16] found that students from elementary to high school show beneficial relationships between parental involvement and student motivation (i.e., school engagement, perceived competence, perceived control, self-regulation, mastery goal orientation, and motivation to read) [16]. When schools implement practices to include parents, parents (regardless of ethnicity or socio-economic background) become more involved and forge closer relationships with schools [20].

Some of the most comprehensive studies on early childhood education and parental involvement were conducted in the 1980-90s on the Chicago Child Parent Center (CPC) Program. These centers service mostly black, low-income, four- to six-year-old children and their parents. Graue et al. [17] studied over 900 students participating in the CPC program from 1983-1986. They found that instructional approaches that blended teacher-directed focus with childinitiated activities and parental school involvement were the basis of long-term effects from participation in the CPCs. Parental involvement was significantly associated with higher levels of school readiness and word analysis skills. Changes in parenting practices and family-school relations enhanced children's school achievement and social adjustment, and contributed to long-term effects of preschool participation [17]. Results from other studies on the CPCs found that after finishing their early childhood education in these centers, reading scores for both genders were equal to local and national norms. In addition, parents' attitudes about their children's education was notably better after participation in the CPC program activities [11].

Increased parental involvement has important effects regardless of race or socio-economic status. Lin [23] found that the percentage of variance in literacy and math skills that was explained by parent involvement was greater for minority children than for European-American children, and for poor children than for the non-poor children. Even though educational resources at home were fewer in both low-income and minority (especially black and Hispanic) homes, a stronger relationship was found among school involvement, home resources, and early literacy. The author concludes that schools need to create school involvement opportunities, particularly for low-income and minority parents, and that parent involvement should also be emphasized in pre-service teacher's training [23].

Higher levels of parental involvement could result in improved achievement because low-income and minority families are less likely to have informal social networks that include parents of other children in the school [18]. Thus, these parents' presence in the classroom may provide them with information about skills required by the teacher, and 
enhance their ability to promote and nurture these skills in their children, which is especially important for mathematics performance. In some cases, parents' had better skills for promoting reading performance than for mathematics [18]. Encouraging parent engagement relies in part on parent satisfaction with their experience with various aspects of their child's early education program. The higher the parental satisfaction with their interactions with an early childhood education program, the higher their level of participation in school-based activities $[10,26]$.

\subsection{Parents' Use of Home Activities}

Recently, studies have begun to focus specifically on early academic achievement resulting from parent involvement with special home activities. Klein, Starkey \& Clements [20] conducted a randomized controlled trial of 40 Head Start and state preschool classrooms to test whether a pre-kindergarten mathematics intervention was effective. The intervention included not only training for treatment teachers, but also for parents in how to use specially created math activities at home. Intervention and control group pre-tests math scores for early math knowledge did not differ; however, post-test results showed significant gain by intervention children over control children. The researchers concluded that including program materials to be sent home to parents helps increase parent engagement with children and helps to positively augment the classroom curricula [20].

In another study, LeFevre et al. [22] studied 146 children in kindergarten through $2^{\text {nd }}$ grade. They considered two types numeracy activities: direct activities (counting, recognizing digits) and indirect with quantitative components (board games with dice, measuring while cooking, shopping). Ultimately, the child's mathematical skills as tested at school correlated with the frequency with which parents reported engaging in informal activities outside of school that have quantitative components. The researchers noted that mathematical learning activities are valuable when they occur in a variety of contexts. For instance, children participating in board games and number-based storybooks showed substantial gains in early numeracy skills. Children's indirect experiences with numbers, particularly in motivating contexts such as games, may be important contributors to their preparation for numeracy experiences in the early grades. Therefore, parentdirected home activities can play a crucial role in mathematical preparation for young children [22].

\subsection{Transmedia as an Educational Tool}

Studies have explored the benefits of transmedia as one of the ways to supplement out of school time (OST) learning and encourage motivation in both formal and informal learning environments. Building on the theory of developmental psychologist Vygotsky [41], it has been suggested that play is an important element in transmedia learning [2]. For Vygotsky, play was not an activity distinct from the real world, but rather a context that can liberate children from many social constraints in which the child's behavior usually occurs. Barab and colleagues [2] argue that designers of transmedia curricula have a unique opportunity to leverage play in their designs, to make interactives that are engaging and meaningful to students. This involves building sociotechnical structures that engage users, allow for a continual growth of individuals within the communities in which they are nested, and encourage active learner, child-centered, inquiry-based learning [2]. In transmedia learning environments, students can extend their learning time and space in and across both school and OST activities, while experiencing the affordances of game-like, narrative-based curricular materials, enhancing their motivation and engagement in the learning process $[21,28]$. Though research on transmedia-related educational programs is still in its infancy, a number of studies have found positive impacts, including active involvement of the audience in the narrative, creation of a unified learning experience, improvement of the learning process by means of integrating knowledge and skills, and gains in student achievement [1,13,6,25,30,31].

\section{STUDY DESIGN AND METHODOLOGY}

The study of PBS KIDS Mathematics Transmedia Suites in preschool homes used a quasi-experimental, non-equivalent groups design, which randomly assigned two Head Start sites to either an intervention or comparison group. The study took place over eight weeks in the summer of 2012. The intervention was based on three PBS KIDS transmedia suites and was comprised of three overarching mathematics concepts found in those suites: numbers and operations in base ten, measurement and data, and geometry and spatial sense. The eight-week intervention encouraged participating parents and children in the intervention group to work together on PBS KIDS transmedia activities for 30 minutes per day for four days per week, and encouraged parents to attend weekly parent meetings at their child's preschool.

Each week of the intervention focused on a specific mathematics concept and included four days of activities for children at home (all hands-on activities in the program were taken from PBS KIDS LAB home activities). During each week of the study, parents in the intervention group met at their child's preschool for one hour. During each parent meeting, parents were encouraged to describe the activities they undertook with their children the previous week; whether they felt their children learned from those activities; and what challenges they had encountered. The comparison group was a "business-as-usual" comparison group in which child/parent dyads received intervention or instruction they would normally receive if the study of PBS KIDS Mathematics Transmedia Suites in preschool homes were not taking place.

Researchers recruited 90 child/parent dyads through two Head Start centers primarily serving families from a lowincome community in Richmond, CA (mean age of child participants $=4$ years, 5 months). Students in the study were primarily from low-income households, with two thirds of the students eligible for free or reduced price meals. About half of the students were Hispanic or Latino with significant subgroups of African American and Asian students. About one third of the students were English-language learners and 14\% of the students received special education services.

\section{INSTRUMENTS}

\subsection{Test of the Early Mathematics Ability (TEMA)}

The Test of Early Mathematics Ability, third edition, is a primary test of children's informal and formal mathematics knowledge, developed by Western Psychological Services. It is a standardized, nationally normed achievement test [15]. The test is designed for use with children ages 3 years, 0 months through 8 years, 11 months. It measures four categories of informal mathematics: Numbering, Number Comparisons, Calculation, and Concepts. It also measures four categories of formal mathematics: Numeral Literacy, Number Facts, Calculation, and Basic 10 Concepts. The test contains 
72 items (each item may have multiple problems) in two forms. The TEMA-3 is not a timed test, and no precise time limits are required for children being tested. Depending on children's mathematics ability, children will be able to complete all 72 items or the relevant portion of the test. On average, it takes 45-60 minutes to administer.

The test examiner's manual reports an alpha of 0.94 for Form A and an alpha of 0.96 for Form B [15, p.32]. The manual also discusses test content-description validity, criterion-prediction validity, and construct-identification validity. The test has been matched for content coverage and difficulty.

For the purposes of this study, the TEMA-3 experimental score was used to analyze children's mathematics ability. The experimental score is simply the number of problems scored correct on the TEMA-3 (one point per correct response). Each TEMA-3 item may have multiple problems. The total number of problems in the TEMA-3 is 201. Therefore, the experimental score ranges from 0 to 201. The TEMA-3 Form A was used as a pre/post measure for children. The pre-test was administered to students after they were assigned to the intervention or comparison condition in mid-June of 2012; the post-test was administered in late July and early August of 2012 at the conclusion of the study.

\subsection{Researcher-Developed Measure of Mathematics Skills}

Given that the TEMA-3 only tests children's numerical sense, WestEd researchers developed a measure of mathematics skills that addressed the remaining two mathematics concepts that are practiced in the transmedia suites: Measurement and Data, and Geometry and Spatial Sense. The researcher-developed measure of mathematics skills includes 15 items and measures three early mathematics concepts: Numbers and Operations in base ten (six items), Measurement and Data (five items), and Geometry and Spatial Sense (four items). The researcher-developed measure of mathematics skills is not a timed test, and no precise time limits are required for children being tested. On average, it takes 15-20 minutes to administer the test.

The scores from the researcher-developed measure of mathematics skills were calculated by summing the number of items scored partially correct (one point per partially correct response) and the number of items scored correct (two points per correct response). Partially correct responses are not available for six items; therefore, the scores range from 0 to 24 . The 15 items showed good reliability on the pre-test (alpha $=.80)$ and on the post-test (alpha $=.82)$. Both the pre-test and post-test of the researcher-developed measure of mathematics skills were administered in conjunction with the TEMA-3 test. Students were randomly assigned to be tested by either the TEMA-3 or researcher-developed measure of mathematics skills first. The order of the tests was the same for any given student for pre-test and post-test.

\subsection{Weekly Fidelity Survey}

Each week, all intervention parents were asked to respond in a survey about activities from the previous week including: (1) which activities/games they played with their children, (2) how long their children played the activities/games, (3) how their children liked the activities/games, and (4) whether they had anything to share regarding the activities.

\subsection{Electronic Usage Log}

The Chromebooks and a custom-designed WestEd website were configured in order to track activities and log when participants accessed the PBS KIDS transmedia suites, which games from the suites were accessed, and approximately how long participants used each game. Researchers configured the Chromebook settings and installed a browser plug-in to redirect study participants to the custom WestEd website, such that the website and PBS KIDS games were the only online sites participants could access. The custom PBS/WestEd website used a login system that connected to Google Analytics. Each time participants logged in to PBS KIDS LAB via the custom website, their username was identified within Google Analytics. This allowed researchers to identify usage data from study participants. Data was downloaded from Google Analytics and compiled by WestEd researchers.

\subsection{Parent Surveys}

Two scales were adapted from the Home Learning Environment (HLE) survey [41] to gauge parent awareness of their child's mathematics development and the available resource at home to support the child's learning. The HLE is a parent survey of home mathematics activities. This survey includes three sections. The first section is a demographic section that acquires parents' education, ethnicity, preferred language at home, and their relationship with the child. The second section obtains parents' awareness of their children's mathematics development. The third section asks parents to report on the types of activities that their children did last week and how frequently their children did each activity alone, with another child, and with an adult.

\section{DATA ANALYSIS METHODS}

A general linear model with pre-tests as covariates was utilized to investigate the impact of Ready To Learn's three mathematics-related PBS KIDS transmedia suites, along with their corresponding parent support materials available on PBS KIDS LAB, on children's outcomes after accounting for the pre-existing differences in the pre-intervention baseline measures. This method is preferred for analyzing pre/post design data because it can eliminate systematic bias and reduce error variance $[5,8]$. The method takes into account regression toward the mean [4], which refers to the concept that when a first measurement of a variable is an extreme value it will tend to be closer to the average on a later measurement. Given that regression toward the mean is a relatively common phenomenon, the researchers applied a general linear model with pre-tests as covariates in this study to increase statistical power and obtain a more precise and less biased estimate of the group effects $[5,8,19]$. In this study, researchers compared the intervention group's postintervention outcomes with the comparison group's postintervention outcomes after adjusting for differences in baseline test results, baseline parents' awareness of children's mathematics development, and participant demographic characteristics (i.e., race/ethnicity and child age). Two student outcomes as measured by the TEMA-3 and researcherdeveloped measure of mathematics skills were used as dependent variables. The intervention status (intervention vs. comparison) was used as the independent variable. Adjusted intervention and comparison group means were reported for each outcome variable. 
Table 10. Impact Analysis of Student Outcome Measures

\begin{tabular}{|c|c|c|c|c|c|c|}
\hline \multirow[b]{2}{*}{ Impact Measure } & \multicolumn{6}{|c|}{ Adjusted Mean } \\
\hline & $\begin{array}{l}\text { Intervention } \\
\text { (Standard } \\
\text { Error) } \\
\end{array}$ & $\begin{array}{l}\text { Comparison } \\
\text { (Standard } \\
\text { Error) } \\
\end{array}$ & $\begin{array}{l}\text { Difference } \\
\text { (Standard } \\
\text { Error) } \\
\end{array}$ & $p$-value & $\begin{array}{l}95 \% \\
\text { Confidence } \\
\text { Interval } \\
\end{array}$ & $\begin{array}{l}\text { Sample } \\
\text { Size }\end{array}$ \\
\hline $\begin{array}{l}\text { TEMA-3 } \\
\text { (Experimental } \\
\text { Scores) }\end{array}$ & $\begin{array}{l}36.71 \\
(1.24)\end{array}$ & $\begin{array}{l}31.89 \\
(1.24)\end{array}$ & $\begin{array}{l}4.82 * * \\
(1.63)\end{array}$ & .004 & $1.58-8.06$ & 90 \\
\hline $\begin{array}{l}\text { Researcher- } \\
\text { Developed Measure } \\
\text { of Mathematics } \\
\text { Skills }\end{array}$ & $\begin{array}{l}11.35 \\
(.62)\end{array}$ & $\begin{array}{l}10.65 \\
(.62)\end{array}$ & $\begin{array}{l}0.70 \\
(.89)\end{array}$ & .435 & $-1.08-2.48$ & 90 \\
\hline
\end{tabular}

Several approaches were utilized to address missing data. For outcome measures, missing item responses were treated as incorrect responses. Participants who missed all the items in the outcome measures were removed from the corresponding analyses. Participants who had more than $10 \%$ of missing data on the covariates were also removed from the impact analysis. Series mean method was utilized to replace the other missing data on the covariates.

Qualitative data collected from open-ended survey questions and weekly focus groups were analyzed using grounded theory, or constant comparative analysis [39]. In an initial data reduction approach, respondents' comments were reviewed and assigned categories of meaning (open coding). Then, these categories along with quantitative data results were reviewed for causal linkages and non-causal relationships related to the central phenomenon (axial coding), which allowed the researcher to develop a "story" that connects the categories (selective coding) and, finally, posit hypotheses or theoretical propositions. These qualitative analyses provided descriptions of 1) how child/parent dyads used the three mathematics-related PBS KIDS transmedia suites, along with their corresponding parent support materials available on PBS KIDS LAB, and 2) how the PBS KIDS transmedia suites, along with their corresponding parent support materials, may increase parents' awareness and support of their children's mathematics learning at home.

\section{IMPACT RESULTS}

\subsection{Fidelity of Implementation at the Intervention Site}

During the eight-week study, families in the intervention condition were presented with a program that included a total of 14 hands-on home activities (two activities per week) and 30 online games (three core program games and three additional games per week $)^{2}$. Electronic usage logs and fidelity surveys were collected from week one through week seven.

Based on the electronic usage logs, on average, child/parent dyads played the online games three days per week. The majority $(97.8 \%)$ of the child/parent dyads in the intervention group played the online games at least one day a

\footnotetext{
${ }^{2}$ All games are from the three target suites and one shape game is from the Dinosaur Train transmedia suite. Some games may be provided in more than one week.
}

week for five weeks, with $64.4 \%$ of child/parent dyads playing the online games every week during the intervention. In addition, child/parent dyads played the online games for an average of 1,213 minutes across seven weeks (173 minutes per week). The most frequently played games included: Huff Puffa-Tron and The Great Shape Race from The Cat in the Hat Knows A Lot About That suite; Hide \& Seek, Apple Picking, Blast Off, Hat Grab, Fair Shares, and Monkey Jump from the Curious George suite; and Vegetable Harvest from the Sid the Science Kid suite. According to the fidelity surveys, parents were also actively involved in the hands-on home activities related to the online games. Parents and children used handson home activities for 20-40 minutes per week. The majority of the child/parent dyads used the hands-on home activities every week $(88.9 \%)$.

\subsection{Children's Knowledge and Skills in Mathematics}

The results indicate that the intervention was positively associated with gains in children's knowledge and skills in mathematics, as measured by the TEMA-3. Adjusted mean differences on the post-test measure of the TEMA-3 show that the intervention group exceeded the comparison group (point estimate of 4.82; effect size $=0.27$ ). Effect sizes of this level are typical in educational interventions and are of sufficient magnitude to close achievement gaps across subpopulation groups [36]. This difference was significant at the .01 level, after accounting for differences in baseline test results, baseline parents' awareness of children's mathematics development, and participant demographic characteristics (i.e., race/ethnicity and child age). However, the intervention was not significantly associated with gains in children's knowledge and skills in mathematics, as measured by the researcherdeveloped measure in mathematics skills (see Table 10). Analysis of each individual measure in mathematics skills item also did not show pre/post group differences. One possible explanation for these outcomes is that games and activities in the intervention focused primarily on numerical sense, which was measured by the TEMA-3. The majority of the intervention program included activities and games related to numerical sense, such as numbers, counting, counting backwards and skip counting, adding, and comparing. Only two weeks of the intervention program featured activities and games that emphasized shapes and sorting (this mirrored the distribution of skills across the games in the transmedia 
suites). In addition, the researcher-developed measure of mathematics skills was only 15 items long and only tested a small subset of skills related to measurement and data, and geometry and spatial sense. These included a limited number of items that tested sorting (three items) and shapes (four items), which may not be sensitive enough to detect changes.

\subsection{Parents' Awareness and Support of their Children's Mathematics Learning}

\subsubsection{Involvement in Children's Play}

The study findings suggest that Ready To Learn's three mathematics-related PBS KIDS transmedia suites, along with their corresponding parent support materials available on PBS KIDS LAB and the parent meetings, provide parents a platform to involve themselves in their children's mathematics learning. Parents who participated in the intervention were encouraged to play six core games with their children per week (two hands-on games, and four online games). Researchers analyzed the average number of games that parents played with their children per week. This information was derived from questions on the weekly fidelity surveys regarding their engagement in the activities. In general, the parents played more than five games per week with their children $(\mathrm{M}=5.43, \mathrm{SD}=0.86)$, which indicated a high level of engagement in their children's play with PBS KIDS transmedia games and the supporting hands-on home activities.

The target population of this project was economically disadvantaged preschool families. These parents, like all parents, want their children to succeed in school. The current project fostered a welcoming environment to encourage parent involvement in their child's learning by providing the intervention program materials, weekly parent meetings to support the understanding and utilization of the program, and technical assistance to answer questions and address concerns. As evidenced by data from the weekly fidelity surveys and focus groups, parents were: interested in the project, felt welcomed and supported, and were willing to be involved in their children's learning. The following quotes, taken from completed fidelity surveys and transcripts of focus groups, are typical of parents' comments about the awareness of the importance in their child's learning.

Thank you for the opportunity that this program is providing to help our children and to help us parents, so we help our children to prepare and advance in their studies, which helps us to get involved more with them and to know about their educational development.

This is very important for me and my family. This program is very good for my children and not just for the child that participates, but for all those who play the games. I am happy to be able to help my child with the help of you all.

According to parents' reflections on the weekly fidelity surveys and focus groups, parents viewed their role as facilitators and/or teachers. Through involvement in their children's play, parents realized that their children enjoy learning when they help them get started, explain what they do not understand, or just keep them company.

I used the fruit and the flowers a lot to [teach him to] count and for colors. He loved it. Now he is constantly doing it outside of home. Pointing at objects and guessing what color it is.

My daughter really enjoys learning and she told me she has so much fun working on the computer with me. I can see her learning more.

Parents reported feeling empowered to support their children's mathematics learning. They felt proud of their children's progress. A grandmother of a participating child, who typically attended the meetings with the mother and the child, shared her excitement upon seeing her grandchild playing with the computer games for the first time. Apparently, another older child in the family wanted to use the computer to show the child other games, but the child responded, "I want to do it myself." Hearing this, the grandmother said she felt proud that her grandchild was successful at working on the computer by himself. Similar statements indicated that parents felt empowered to teach their children because of the teaching and learning resources provided by the intervention materials.

We love these [parent meetings], because they teach me how to learn to educate better my daughter. I am getting practical and simple advice, which is also very enjoyable. I think that she is having fun and learning and I am thankful for these activities that are so creative, and the enrichment for all the families.

My child and I enjoyed participating in this study. She was able to learn a lot about numbers, and I learned different ways to teach her. PBS is a great learning resource.

This program is not only teaching our children but the whole family, like grandparents and aunts and uncles. It is important to me that we are getting more ideas to help our children.

\subsubsection{Awareness of Children's Mathematics Interests}

Mathematics provides children with the foundation for problem-solving and reasoning abilities, as well as critical thinking skills. However, parents may not be aware of their children's mathematics learning and may not understand how the mathematics skills their children are learning relate to everyday life. Data analysis suggests that the current project assisted families with understanding children's mathematics development, helping them to create conditions at home to promote mathematics activities, and to apply PBS KIDS online mathematics games to support children's mathematics learning.

To detect whether interacting with children around the PBS KIDS transmedia suites and using related support materials increases parent's awareness of their children's mathematics learning at home, researchers analyzed the composite sum scores for intervention parents' awareness of their children's mathematics development. This information was derived from parent survey questions on their knowledge about typical preschool children's mathematics abilities and skills. The results indicated that parents' awareness of their children's mathematics development significantly increased over the course of the intervention (Pre $M=8.65$ (2.01), Post $M=10.26$ (1.38), $d f=42, p<$ $.001)$.

Analysis of fidelity survey and focus group data suggests that parents were surprised at the depth of their children's 
mathematics skills:

I was surprised that my child knew the names for pentagons and octagons, when I had forgotten them.

I am very impressed that my son is using operations, geometry, spatial sense, measurement, data collection and analysis, algebraic thinking. I will continue to include them when we learn.

I was surprised that he knew what the missing number was so quickly. At first I thought it was him taking a guess, but when he kept getting them correct it surprised me.

Through working with their children on the PBS KIDS transmedia suites, parents identified their children's interest areas and the potential challenges their children were facing:

She likes Count with Allie. She liked giving the dogs doggy bones. Museum of Tens--she liked playing because all of the different things on the wall and counting them.

In the game with the different activities, I saw him very motivated, counting which were missing to complete the quantity of 10. In the game of completing the tens, he had difficulty at the beginning, but I saw him very concentrated to not mess up and do it better. At the end he did it very well. In the vegetable activities, I saw him very attentive seeing which were missing and he liked where he had to complete the shapes of snow. I saw my child very attentive when he had to search in the snow to find the houses that are buried in the snow. The other activities I knew that he understood because some he had already done well in the classroom before.

He had a hard time with [one] game. He has numbers memorized and can recognize a few by letter, but asking for it in a sequence, like the game did, was a bit challenging for my son.

The study results suggest that the intervention program helped parents think about their child's mathematics learning in the home environment. They also suggest the three mathematics-related PBS KIDS transmedia suites, along with their corresponding parent support materials available on PBS KIDS LAB, helped parents support their child's mathematics learning over the course of the eight-week intervention. In addition, parents indicated they would continue to support their children's mathematics learning.

\section{CONCLUSION}

This CPB-PBS Ready To Learn study was designed to test whether the use of PBS KIDS transmedia suites and related support materials increases children's mathematics ability and increases parents' awareness and support of their children's mathematics learning at home. The results indicate that children who were exposed to the PBS KIDS transmedia suites and related support materials in the summer of 2012 outscored their comparison group peers on the TEMA-3, by 4.82 problems with an effect size of 0.27 . This difference was significant at the 0.01 level. TEMA-3 is a widely used, standardized, nationally normed achievement test. It measures children's numerical sense, which is the primary focus of the intervention. The treatment group's significant improvement in performance on this assessment shows the impact of the intervention on children's numerical sense development. Children's mathematics ability was also assessed using a researcher-developed measure of mathematics skills. The results indicated no observed differences between the intervention and comparison groups in children's mathematics ability on the small subset of skills covered by the assessment.

The results related to parents' awareness and support of their children's mathematics learning at home indicate that parents were highly involved in supporting their children's mathematics learning. They viewed themselves as facilitators and/or teachers when working with their children. They also felt empowered to teach their children using knowledge gained from the intervention program. Through the intervention program, parents became more aware of their children's mathematics ability. For instance, parents began to identify what their children could do in mathematics, what their children's areas of interest in mathematics were, and what potential challenges their children were facing.

A joint position statement by two leading professional organizations in early childhood and mathematics, the National Association for the Education of Young Children and the National Council of Teachers of Mathematics, assert that early childhood mathematics education should apply children's everyday activities and should continue to introduce or expand upon important mathematics ideas [27] (National Association for the Education of Young Children and National Council of Teachers of Mathematics, 2002). Educators and parents may be looking for ways to strengthen their formal and informal mathematics education for young children. The current intervention program responds to this position recommendation and the needs in early childhood mathematics education by utilizing three PBS KIDS transmedia suites as the platform to encourage children's mathematics learning. The current intervention program uses the transmedia suites to weave mathematics into children's lives through the use of popular PBS KIDS properties, such as The Cat in the Hat Knows A Lot About That, Curious George, and Sid the Science $\mathrm{Kid}$. It also introduces easily adopted and adapted hands-on home activities for parents. Parents can use the PBS KIDS transmedia suites and related support materials as resources to incorporate early mathematics activities into their children's daily lives and their home environment. We envision this study as a pioneering effort to stimulate a series of practical home intervention models to examine whether transmedia platform, with its increasingly pervasive presence in family life and steeply rising usage rates among low-income families, can serve as an effective tool in connecting home and school learning.

\section{ACKNOWLEDGMENTS}

The authors would like to acknowledge the valuable contributions of a number of organizations and individuals to this study. We would like to thank the U.S. Department of Education's Ready To Learn Initiative, the Public Broadcasting Service and the Corporation for Public Broadcasting for their generous support. Thanks also to Contra Costa County Community Services Bureau for their valuable support and feedback. We also truly appreciate the Head Start teachers and directors who supported us throughout the course of this study. We would also like to acknowledge the dedication and contributions of research staff Alice Klein, Prentice Starkey, Sophie Vogel, Amber Busby, Ursula Sexton, Leslie Banes, Liz Mellinger, Yvonne Kao, Marycruz Diaz, Rebeca Diaz, Claire Morgan, David Borrelli, Mykael 
Thompson, Ruthie Chang, Hannah McCarthy, Katherine Kuhns, and Jennifer Rochin. Finally, we would like to thank all children and parents who took part in the PBS KIDS Mathematics Transmedia Suites in Preschool Homes study.

\section{REFERENCES}

[1] Andreu, L., Marti, J., \& Aldas, J. (2012). The use of digital transmedia storytelling for case studies in marketing education. INTED2012 Proceedings, 14061414.

[2] Barab, S., Thomas, M., Dodge, T., Carteaux, R., \& Tuzun, H. (2005). Making learning fun: Quest Atlantis, a game without guns. Educational Technology Research and Development, 53(1), 86-107.

[3] Becker, H. J., \& Epstein, J. L. (1982). Parent involvement: A survey of teacher practices. The Elementary School Journal, 85-102.

[4] Bland, J.M. \& Altman, D.G. (1994). Statistic Notes: Regression towards the mean. British Medical Journal, 308, (6942): 1499.

[5] Bonate, P.L. (2000) Analysis of Pretest-Posttest Designs. London, England: Chapman \& Hall.

[6] Cohen, J., Ducamp, G., Kjellstrom, W., \& Tillman, D. (2012). What happens when children encounter the Tbook?: The potential for transmedia books in teacher education. Society for Information Technology \& Teacher Education International Conference, 2012(1), 1033-1040.

[7] Dearing, E., McCartney, K., \& Taylor, B. A. (2009). Does higher quality early child care promote Low-Income children's math and reading achievement in middle childhood? Child Development, 80(5), 13291349.

[8] Dimitrov, D.M. \& Rumrill, P.D. (2003) Pretest-Posttest Designs and Measurement of Change. Work 20, 159165.

[9] Fan, X., \& Chen, M. (2001). Parental involvement and students' academic achievement: A meta-analysis. Educational Psychology Review, 13(1), 1-22.

[10] Fantuzzo, J., Perry, M. A., \& Childs, S. (2006). Parent satisfaction with educational experiences scale: A multivariate examination of parent satisfaction with early childhood education programs. Early Childhood Research Quarterly, 21(2), 142-152.

[11] Fuerst, J. S., \& Fuerst, D. (1993). Chicago experience with an early childhood program the special case of the child parent center program. Urban Education, 28(1), 69-96.

[12] Galinsky, E. (2006). The economic benefits of highquality early childhood programs: What makes the difference? CED.

[13] Gilardi, F., \& Reid, J. (2011). E-learning through transmedia storytelling: How the emerging internetbased participatory cultures in China can be co-opted for education. Global Learn Asia Pacific, 2011(1), 14691474.

[14] Ginsburg, H. P., \& Russell, R. L. (1981). Social class and racial influences on early mathematical thinking.
Monographs of the Society for Research in Child Development, 46 (6, Serial No. 193).

[15] Ginsburg, H., \& Baroody, A. (2003). Test of Early Mathematics Ability--Third Edition. Austin, TX: Pro-Ed

[16] Gonzalez-DeHass, A. R., Willems, P. P., \& Holbein, M. F. D. (2005). Examining the relationship between parental involvement and student motivation. Educational Psychology Review, 17(2), 99-123.

[17] Graue, E., Clements, M. A., Reynolds, A. J., \& Niles, M. D. (2004). More than teacher directed or child initiated: Preschool curriculum type, parent involvement, and children's outcomes in the child-parent centers. Education Policy Analysis Archives, 12(72), $\mathrm{n} 72$.

[18] Hill, N. E., \& Craft, S. A. (2003). Parent-school involvement and school performance: Mediated pathways among socioeconomically comparable African American and Euro-American families. Journal of Educational Psychology; Journal of Educational Psychology, 95(1), 74.

[19] Keppel, G. \& Wickens, T.D. (2004). Design and analysis: A researcher's handbook (4th ed). Upper Saddle River, NJ: Pearson - Prentice Hall.

[20] Klein, A., Starkey, P., Clements, D., Sarama, J., \& Iyer, R. (2008). Effects of a pre-kindergarten mathematics intervention: A randomized experiment. Journal of Research on Educational Effectiveness, 1(3), 155-178.

[21] Lacasa, P. (2010). Children transmedia and virtual experiences inside and outside the classrooms. SL Wong et al, 663-667.

[22] LeFevre, J. A., Skwarchuk, S. L., Smith-Chant, B. L., Fast, L., Kamawar, D., \& Bisanz, J. (2009). Home numeracy experiences and children's math performance in the early school years. Canadian Journal of Behavioural Science/Revue Canadienne Des Sciences Du Comportement, 41(2), 55.

[23] Lin, Q. (2003). Parent involvement and early literacy. Harvard Family Research Project,

[24] Magnuson, K. A., \& Waldfogel, J. (2005). Early childhood care and education: Effects on ethnic and racial gaps in school readiness. The Future of Children, 15(1), 169-196.

[25] McCarthy, B., Li, L., \& Tiu, M. (2012). PBS KIDS mathematics transmedia suites in preschool homes. WestEd.

[26] McWayne, C., Campos, R., \& Owsianik, M. (2008). A multidimensional, multilevel examination of mother and father involvement among culturally diverse head start families. Journal of School Psychology, 46(5), 551-573.

[27] National Association for the Education of Young Children (2002). Early Childhood Mathematics: Promoting Good Beginnings. Washington, D.C. National Association

[28] National Center for Education Research (2008). Effects of preschool curriculum programs on school readiness. Report from the preschool curriculum evaluation research initiative. NCER 2008-2009.

[29] Pace, R. (2011). Learning history writing and reading a story. Multimodal texts as a teaching tool. Oralité (s) et écriture (s), 65.

[30] Paulsen, C. A., Green, S., \& Carroll, S. (2011). Design squad nation: Evaluation executive summary. Concord, MA: Concord Evaluation Group, LLC. 
[31] Pence, H. E. (2011). Teaching with transmedia. Journal of Educational Technology Systems, 40(2), 131-140.

[32] Reynolds, A. J. (1991). Early schooling of children at risk. American Educational Research Journal, 28(2), 392-422.

[33] Reynolds, A. J., Ou, S. R., \& Topitzes, J. W. (2004). Paths of effects of early childhood intervention on educational attainment and delinquency: A confirmatory analysis of the Chicago Child-Parent centers. Child Development, 75(5), 1299-1328.

[34] Reynolds, A. J., \& Temple, J. A. (1998). Extended early childhood intervention and school achievement: Age thirteen findings from the Chicago longitudinal study. Child Development, 69(1), 231-246.

[35] Sarama, J., Clements, D. H., Starkey, P., Klein, A., \& Wakeley, A. (2008). Scaling up the implementation of a pre-kindergarten mathematics curriculum: Teaching for understanding with trajectories and technologies. Journal of Research on Educational Effectiveness, 1(2), 89-119.

[36] Schochet, P.Z. (2005). Statistical power for random assignment evaluations of education programs. Princeton, NJ: Mathematics Policy Research.
[37] Starkey, P., Klein, A., \& Wakeley, A. (2004). Enhancing young children's mathematical knowledge through a pre-kindergarten mathematics intervention. Early Childhood Research Quarterly, 19(1), 99-120.

[38] Starkey, P., Klein, A., Chang, I., Dong, Q., Pang, L., \& Zhou, Y. (1999). Environmental supports for young children's mathematical development in China and the United States. Paper presented at the meeting of the Society for Research in Child Development, Albuquerque, NM.

[39] Strauss, A. \& Corbin, J.M. (1990). Basics of qualitative research, grounded theory, procedures and techniques. Newbury Park: Sage.

[40] Yoshikawa, H., Rosman, E. A., \& Hsueh, J. A. (2002). Resolving paradoxical criteria for the expansion and replication of early childhood care and education programs. Early Childhood Research Quarterly, 17(1), 3-27.

[41] Vygotsky, L.S. (1978). Mind in society. (N. Cole, V. John-Steiner, S. Scribner, \& E. Souberman, eds.).

Cambridge, MA: Harvard University Press. 